\title{
Hybrid Print Systems: Creating printed textile designs through Motion capture, Visual programming language and Digital inkjet printing technology
}

\author{
Devabrata Paramanik \\ College of Art, Design \& Built Environment \\ Nottingham Trent University \\ Burton Street \\ Nottingham, NG1 4BU \\ devabrata.paramanik@ntu.ac.uk
}

\begin{abstract}
The exploratory part of the project aims to contribute to knowledge by studying the HPS through creative experiments as both a hybrid medium and a hybrid tool as a holistic approach.
\end{abstract}

hybrid prints, motion capture, textile design, programming language

\section{INTRODUCTION}

In Understanding The Media (1964) Marshall McLuhan theorises medium (technology) as an extension of the human body or the mind that acts as agents of change in our experience of the world. Hybridisation of medium results in 'release of great new force and energy as by fission or fusion', meaning this process not only changes form and usage of existing media but our behaviour with such medium. In this project Hybrid Printing System (HPS) is a resultant of the integration of two medium, emerging technologies such as motion-capture technology (MOCAP) and digital textile printing technology (DTPT).

This project draws upon Frayling's proposition of research through art and design (1993), and it is concerned with research towards a developmental and innovative work.

The project attempts to re-examine the potential of closing the gap between art and everyday life by developing objects that fulfil more complex and abstract needs. Design is seen as a form of socioaesthetic research towards the integration of aesthetic experience and everyday life through the development of conceptual products rather than working prototypes or models, which attempt to simulate a final product designed for mass production (Dunn \& Seago 1999).

HPS is an innovative method of creating 'hand made' product through technology.

\section{EXPERIMENT}

In the experiment, visual programming language 'Processing' was coupled with computer vision (web cam) to capture hand movements. The original idea to use programming was to visualise the numerical data generated by MOCAP. These experiments generated abstract print patterns resembling tie-dyed and geometric patterns.

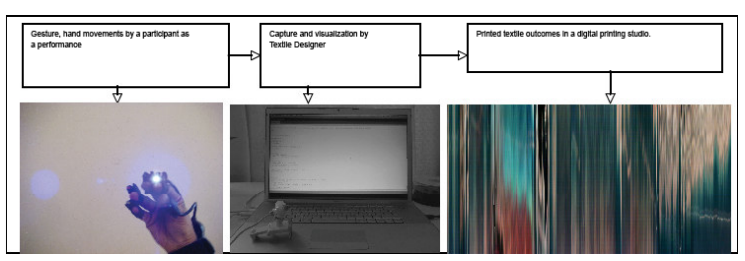

Figure 1: Capturing hand movements via light glove and computer vision to create abstract patterns

The analysis found that the generated pattern as an art form that signifies digital translation could lead to visually unpredictable form, whose meaning resides in the process of translation and it can have a literal meaning that could represent the subject in a new visual sign language (digital media). 


\section{OUTCOMES}

The projections for future research are, capturing hand movements by the above method and manipulation of the data resulted in variety of visually abstract forms, which are applicable to printed textiles and could be used in for future research.

\section{REFERENCES}

McLuhan, M. \& Fiore, Q. 1967, The medium is the massage, Bantam Books, New York.

Frayling, C. 1993. Research in Art and Design, Royal College of Art Papers, 1:1, (1993/4)

Seago, A. and Dunne, A.1999. New Methodologies in Art and Design Research: The Object as

Discourse. Design Issues, 15:2 